Sharif University of Technology
Scientia Iranica
SCIENTIA
IRAN I CA
Transactions A: Civil Engineering
www.scientiairanica.com

\title{
Effect of record scaling on the behavior of reinforced concrete core-wall buildings subjected to near-fault and far-fault earthquakes
}

\author{
H. Beiraghia ${ }^{a, *}$, A. Kheyroddin ${ }^{\text {b }}$ and M.A. Kafi ${ }^{b}$ \\ a. Department of Civil Engineering, Mahdishahr Branch, Islamic Azad University, Mahdishahr, Iran. \\ b. Faculty of Civil Engineering, Semnan University, Semnan, Iran.
}

Received 11 May 2015; received in revised form 15 December 2015; accepted 7 May 2016

\author{
KEYWORDS \\ Reinforced concrete; \\ Core-wall; \\ Near-fault; \\ Far-fault; \\ Record scaling.
}

\begin{abstract}
In this paper, two distinct record scaling methods, Spectrum-Matching (SM) and Amplitude Scaling (AS), were used to study the seismic behavior of reinforced concrete core-wall buildings subjected to Near-Fault (NF) and Far-Fault (FF) strong ground motions. First, the core-walls were designed based on seismic codes. Next, nonlinear fiber element models of the core-walls were prepared using the extended plastic hinge and the single-plastic hinge approaches. The SM and AS methods were used to obtain appropriate records for use in nonlinear time history analysis. Amplitude scaling procedure led to larger curvature ductility demand at the upper levels of the buildings, and this issue was more critical for the near-fault ground motions. On the other hand, SM procedure led to larger curvature ductility demand at the lower levels and less curvature ductility demand at the upper levels. The reason for this difference was the changes in the ground motion characteristics due to SM procedure. The changes in the ground motion characteristic were more severe for near-fault ground motions. For NF records, mean period of the SM records was 0.67 times that of the AS records, and shows that the frequency content of the SM-NF events was affected by SM process.

(C) 2017 Sharif University of Technology. All rights reserved.
\end{abstract}

\section{Introduction}

The use of Reinforced Concrete (RC) core-wall buildings is increasing for the construction of tall buildings, because it offers quick completion of construction, favorable architectural features, and structural behavior [1]. Severe damage to RC wall systems has been reported during strong ground motions [2]. For example, considerable damage to and collapse of RC wall systems have been reported in the recent earthquake in Chile [3].

When a core-wall building is subjected to a

*. Corresponding author.

Email addresses: h.beiraghi@msh-iau.ac.ir (H. Beiraghi);

Ali.kheyroddin@uta.edu (A. Kheyroddin)
Design-Basis Earthquake (DBE) or a Maximum Credible Earthquake (MCE), it is not cost-effective to prevent the extension of plasticity in the entire wall. Building design codes prescribe the use of reduced lateral forces when designing a building. Generally, design codes allow for the occurrence of inelastic behavior in parts of the structural system during strong ground motion. In a cantilever wall, it is preferred for flexural inelastic deformation to occur at the base, which is defined as the plastic hinge region. Single plastic hinge extension at the base of a cantilever shear wall has been recommended by different codes and studies. It should be noted that the rotation of the plastic hinge must be controlled and the upper part of the wall is expected to remain elastic [4-8].

Tall RC cantilevered walls are strongly affected by 
higher mode effects; studies have shown that moment demand is greater than the calculated values obtained from Response Spectrum Analysis (RSA) at the midheight, and that greater than expected shear demand can occur in RC walls [6,9-12]. Codes, such as NAS 3101 , use the concept of capacity design, which, for the seismic design of structures, ensures that the structure responds in an acceptable and ductile manner during severe ground motion [13].

The formation of one plastic hinge at the base of an $\mathrm{RC}$ wall is called the single plastic hinge approach. There is also the extended plastic hinge approach which allows plasticity to develop anywhere along the height of the wall. This approach is not intended to bring about the development of plasticity concentrated in one distinct region along the height of the wall; thus, plasticity is likely to extend to the upper levels of the walls [14].

After the recent earthquakes, engineers and seismologists realized the potential damage that may take place due to the effects of Near-Fault (NF) ground motions on buildings. The damage observed from the recent earthquakes illustrated that structures located within the NF area suffered more severe damage than structures located outside of this zone [15]. Strong (NF) ground motion is usually characterized by a longperiod pulse-like motion in the horizontal direction that includes large displacement and large velocity amplitude [16]. Strong NF earthquakes have shown that structures designed according to recent codes can experience unexpected severe damage [17]. Many studies have demonstrated that buildings located in an NF zone undergo highly inelastic behavior caused by velocity pulses in the fault-normal component of some seismic ground motions $[18,19]$.

Efficient performance-based design requires a rational selection of ground motion records and accurate modeling of structures. Generally, the procedure of selecting, scaling, and matching accelerograms plays a prominent role in dynamic analysis [20].

Research on the behavior of tall RC core-wall buildings subjected to NF motions has shown that tall $\mathrm{RC}$ walls subjected to NF ground motion excitation at the MCE level experience considerable inelastic deformation and considerable floor acceleration that may exceed the Peak Ground Acceleration (PGA) [21]. The inelastic response of tall core-wall buildings subjected to NF seismic ground motion and simple closed-form pulses and parametric studies has shown that if the pulse period is in the range of the second structural modal period, the first and second modes of vibration are significantly excited, leading to a severe inelastic response at the base of the $\mathrm{RC}$ wall. A dual-plastic hinge occurs when one plastic hinge forms at the base and another form at mid-height of the wall. Panagiotou and Restrepo [14] subjected this type of walls to three strong NF ground motions. The results showed that the second plastic hinge in the upper region can reduce the excessive moment.

No previous study has compared the effect of record scaling method on the response of the RC corewall buildings. In this study, Amplitude-Scaling (AS) and Spectrum-Matching (SM) methods were employed to scale the records. The effects of SM scaling method on seismic characteristics of NF and FF records and the changes in the core-wall behavior subjected to these records are not clear. In the present study, 20-, 30-, 40-, and 50-story RC core-wall buildings were designed using existing building codes. To perform the nonlinear time history analysis (NLTHA), one modeling approach is Single Plastic Hinge ( $\mathrm{SPH}$ ) approach; in this approach, only the base region of the core wall was modeled by the nonlinear fiber element, and the upper region was modeled by elastic elements. Another approach is Extended Plastic Hinge (EPH) approach; in this approach, the whole core-wall model was prepared from nonlinear fiber elements. The models were then subjected to FF and NF pulse-like ground motions scaled with AS and SM methods and the results were compared.

\section{Design of high-rise RC core-wall buildings}

The 20-, 30-, 40-, and 50-story model buildings are designed according to existing codes. The gravity load was carried by the peripheral columns and the corewall. Figure 1 shows a typical floor plan. The dead load of the floors was calculated assuming a $20 \mathrm{~cm}$ thick reinforced concrete slab, the weights of the materials totaled $7 \mathrm{kN} / \mathrm{m}^{2}$, and the live load was assumed to be

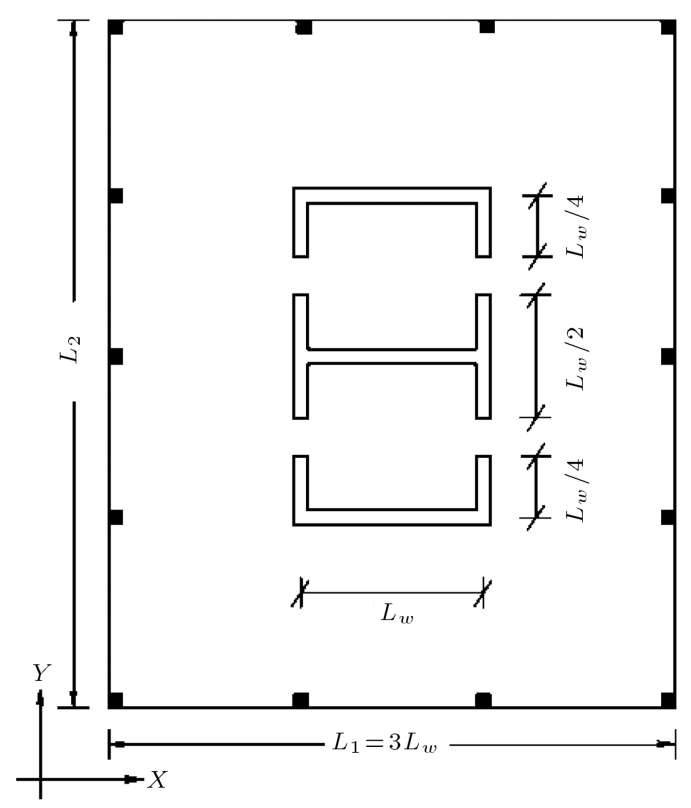

Figure 1. Typical floor plan of study cases. 
$2 \mathrm{kN} / \mathrm{m}^{2}$ (ASCE 7 [22]). The typical story height was $3.5 \mathrm{~m}$, and the base of the walls was fixed.

The case studies were designed using ETABS software version 9.07 to create a 3D linear elastic finite element model of the core-wall. Shell-type elements needed to model the wall are available in ETABS. The shell element uses a triangular or quadrilateral formulation that combines a separate membrane and plate-bending behaviors [23]. The floors and columns are not included in the geometry of the model and only shell elements are used to create the model. In the considered systems, beam does not exist and the post-tensioned slab transfers the gravity load to the columns. The insignificant effect of the perimeter columns and this kind of slabs subjected to lateral load has been demonstrated by other research studies $[1,2,14,21]$. Therefore, the RC core-wall undergoes all the seismic lateral loads applied to the building. The portions for the dead and live loads carried by the core wall were assigned to the wall. Reputable design codes, such as ASCE 7 and ACI 318-11, were used to design the models $[22,24]$. A reduction factor was used to account for crack formation subject to lateral loads. This reduction factor was multiplied by the moment of inertia of the core wall cross-section and was chosen to be 0.5 for the walls in accordance with the stiffness reduction factors recommended in ACI 318-
11 (Sections 8.8 and 10.10). Other standards could be used for this purpose (e.g., ASCE 41-06 [25]).

The nominal yielding strength of the reinforcement was $400 \mathrm{MPa}$, and the nominal compression strength of the concrete was $45 \mathrm{MPa}$. Note that all structural analyses and designs were limited to the $X$ direction. A 5\% damping response spectrum at DBE level was used in RSA (Figure 2). A response modification factor of $5(R=5)$ was used to obtain the elastic design demand from the response spectrum (NEHRP Seismic Design Technical Brief No. 6).

The base shear force calculated by RSA procedure $\left(V_{t}\right)$ becomes equal to 0.85 times the base shear force calculated by equivalent static procedure $(V)$ according to the ASCE 7 (2005). Table 1 shows the design characteristics of the models.

The specifications of the core-walls are shown in Table 1. The thickness of each wall is constant along the height in each model. The longitudinal steel reinforcement distribution is uniform within each crosssection. This was determined, such that the nominal flexural strength at each level was greater than the design moment demand. The reinforcement ratio for every $10 \%$ of height from the base was considered to be invariable. Table 2 shows the longitudinal reinforcement ratio. The boundary element length used complied with ACI-318 and extended to $8 \%, 6 \%, 2 \%$,

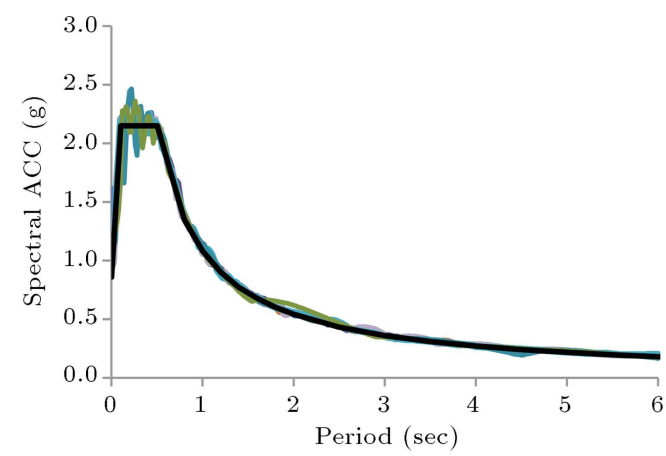

(a) Spectrum-matched result for near-fault motions

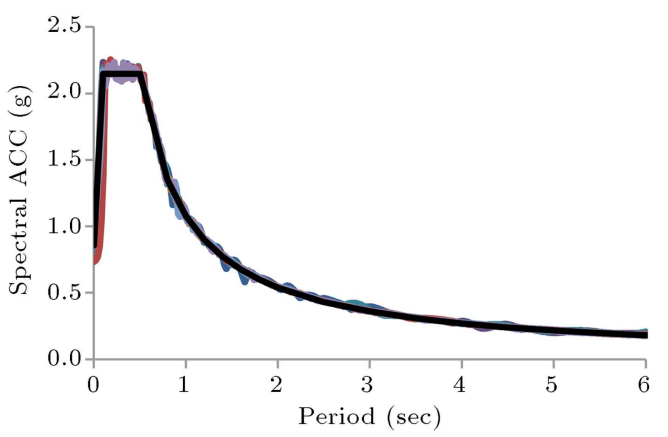

(c) Spectrum-matched result for far-fault motions

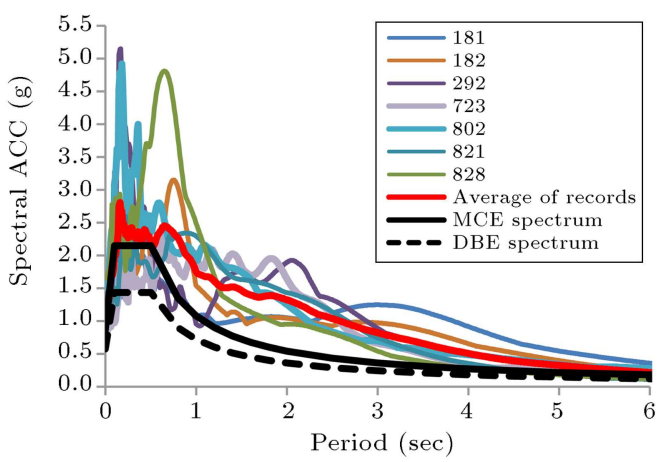

(b) Amplitude-scaled result for near-fault motions for 20-story building

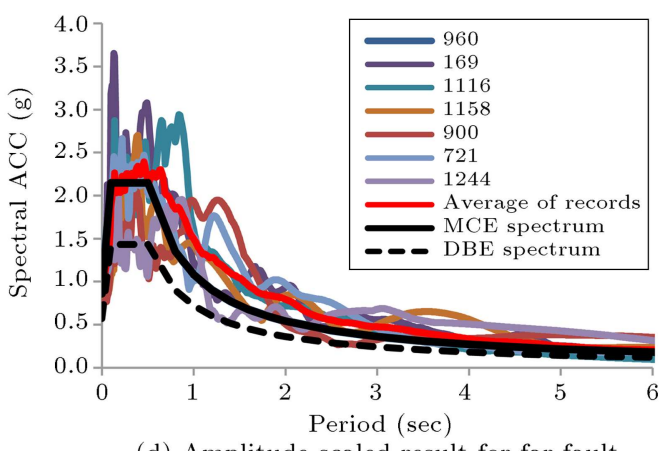

(d) Amplitude-scaled result for far-fault motions for 20-story building

Figure 2. Response spectrum (5\% damping). 
Table 1. Characteristics of core walls.

\begin{tabular}{lcccc}
\hline & \multicolumn{3}{c}{ No. of stories } \\
\cline { 2 - 5 } & $\mathbf{2 0}$ & $\mathbf{3 0}$ & $\mathbf{4 0}$ & $\mathbf{5 0}$ \\
\hline Building height, $H(\mathrm{~m})$ & 70 & 105 & 140 & 175 \\
Core wall thickness, $t_{w}(\mathrm{~m})$ & 0.35 & 0.55 & 1.15 & 1.85 \\
Floor plan dimension $\left(L_{1} \times L_{2}\right)(\mathrm{m})$ & $15 \times 20$ & $22.5 \times 27.5$ & $30 \times 35$ & $37.5 \times 42.5$ \\
Axial stress at the base $P /\left(f_{c} A_{g}\right)$ & 0.116 & 0.122 & 0.133 & 0.151 \\
Core wall yield curvature, $\Phi_{y}(\mathrm{rad} / \mathrm{m})$ & $0.0033 / L_{W}$ & $0.0033 / L_{W}$ & $0.0033 / L_{W}$ & $0.0033 / L_{W}$ \\
Normalized design static base shear force using & 8.5 & 7.3 & 7.3 & 7.2 \\
equivalent lateral force $(\%), V / W$ & 33 & 25.3 & 22.2 & 19.8 \\
Normalized base shear from elastic RSA $(\%), V_{\text {ERS }} / W$ & 5500 & 17500 & 48170 & 103520 \\
Seismic weight, $t$ & &
\end{tabular}

Table 2. Longitudinal reinforcement ratio of core walls.

\begin{tabular}{ccccc}
\hline & \multicolumn{4}{c}{$\begin{array}{c}\text { Longitudinal reinforcement } \\
\text { ratio (\%) }\end{array}$} \\
\cline { 2 - 5 } Height \% & $\mathbf{5}$ st & $\mathbf{3 0}$ st & $\mathbf{4 0}$ st & $\mathbf{5 0}$ st \\
\hline $1-10$ & 1.23 & 1.10 & 0.88 & 0.78 \\
$11-20$ & 0.93 & 0.78 & 0.60 & 0.49 \\
$21-30$ & 0.73 & 0.61 & 0.46 & 0.35 \\
$31-40$ & 0.67 & 0.55 & 0.42 & 0.33 \\
$41-50$ & 0.65 & 0.57 & 0.44 & 0.35 \\
$51-60$ & 0.63 & 0.57 & 0.45 & 0.37 \\
$61-70$ & 0.54 & 0.52 & 0.41 & 0.36 \\
$71-80$ & 0.42 & 0.40 & 0.33 & 0.31 \\
$81-90$ & 0.25 & 0.25 & 0.25 & 0.25 \\
$91-100$ & 0.25 & 0.25 & 0.25 & 0.25 \\
\hline
\end{tabular}

and $0 \%$ of the building height from the base of the core walls for the 20-, 30-, 40-, and 50-story buildings, respectively. For all models, the ratio of total height to the $L_{1}$ (aspect ratio) was 4.67 (Figure 1 ).

\section{Nonlinear modeling}

\subsection{Fiber element modeling}

The ability of the current approaches to model slender RC shear walls has been previously examined, and the results verify the accuracy of the fiber element models. The responses of the fiber model and the experimental data for large-scale slender concrete shear wall specimens under cyclic loading showed good conformity $[26,27]$.

The dynamic behavior of the buildings was estimated using a fiber element approach in Perform$3 \mathrm{D}$ software [28]. Shear wall elements are available to model cantilever walls. Each element uses 4 nodes and has 24 degrees of freedom [29]. The fiber cross-section contains steel and concrete fibers

A confined concrete stress-strain relationship based on the modified Mander model was assumed [30] for nonlinear fiber element modeling of the inelastic area of the SPH and the whole EPH model. The concrete compressive strength was assumed to be 1.3 times the specified strength used for the design, and the yield strength of the steel bar was 1.17 times its nominal yield strength [31]. Therefore, the expected maximum compression strength of confined concrete and the pertaining strain are 58.5 $\mathrm{MPa}$ and 0.0046 , respectively. The tensile strength of the concrete was neglected [31]. Perform-3D utilized four linear segments to approximate the confined concrete stressstrain graph obtained using the Mander model (Figure 3). The stress-strain relationship of the reinforcement steel and its yield strength is shown in Figure 3. Strength and stiffness degradation were considered by specifying the degradation factor for longitudinal

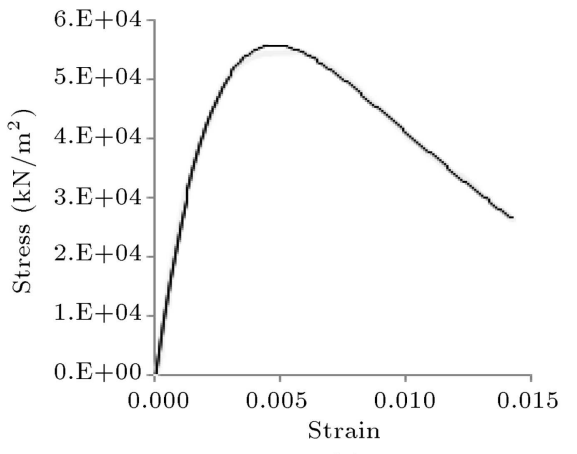

(a)

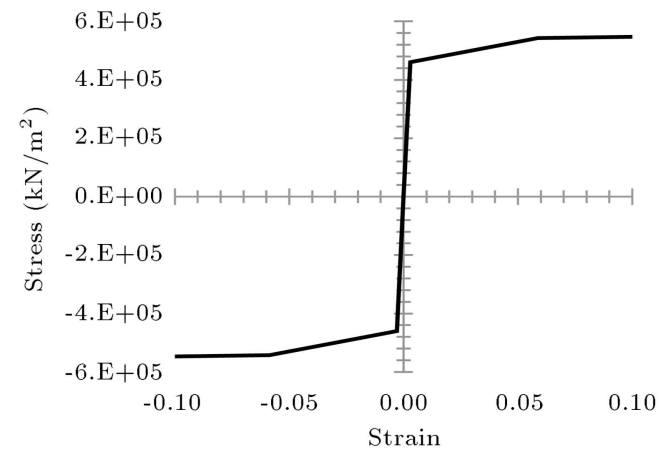

(b)

Figure 3. Strain-stress for (a) compression concrete, and (b) longitudinal steel. 
reinforcements. This factor represents the ratio of the degraded areas to non-degraded hysteresis loops [32]. One element was used per story to model the corewall [29,33].

For SPH cases in which the plastic hinge region occurred at the base of the wall, an inelastic shear wall section was used for the lowest $10 \%$ of the core-wall height adjacent to the foundation [14]. It was assumed that the upper regions would remain elastic; therefore, in the upper levels, elastic shear wall elements were used. For SPH approach, the flexural stiffness of shear wall elements above the inelastic region was set to $50 \%$ of the uncracked elastic stiffness to consider the effective flexural stiffness for the elastic regions of the core-wall (ATC-72 [27]).

\subsection{Damping modeling}

For NLTHA, the assumed damping coefficient is important, and the analysis results can essentially be changed by these coefficients [34]. Inappropriate choices may not simulate the real responses of a structure and are primarily the result of numerical errors [35]. Bernal [36] showed that Rayleigh damping may lead to excessive damping forces. Chopra [37] believed that Rayleigh damping cannot be used unless similar damping mechanisms are provided throughout the structure.

Two modes must be selected to apply Rayleigh damping, and different pairs of modes can be used.
It is common to consider the first mode as it dominates numerous seismic structural responses. Attention should be paid to selection of another mode to calculate Rayleigh damping. It is common to select the first mode and the mode for which accumulated modal mass is greater than $90 \%$ of the total mass. In this study, $2.5 \%$ modal damping for all modes is used in addition to $0.15 \%$ Rayleigh damping for the first and third modes [29].

\section{Ground motion data and scaling}

It is necessary to use a set of earthquake records that represents a specific response spectrum for NLTHA. Seven horizontal ground motion records were selected from the NF record set shown in Table A-6B from FEMA P695 and from the FF record set in Table A-4C from FEMA P695 [38]. The NF motion data are recognized as pulse-type ground motions. All records are fault-normal components of ground motions obtained from the PEER NGA database [39]. The ground motion specifications are shown in Table 3 . To scale the earthquake records through AmplitudeScaling (AS) method, the records were scaled, such that the average value of the $5 \%$ damped spectrum graph for periods ranging from $0.2 T$ to $1.5 T$ was placed above the MCE spectrum curve, where $T$ is the first mode period of the natural vibration [22]. The resulted

Table 3. List of ground motions used for NLTHA.

\begin{tabular}{|c|c|c|c|c|c|c|c|c|c|}
\hline & Event name & $\begin{array}{c}\text { Peer } \\
\text { code }^{a}\end{array}$ & Year & $\begin{array}{c}\text { Record } \\
\text { length (s) }\end{array}$ & Station & $\mathbf{P G A}^{\mathrm{b}}$ & $\mathrm{PGV}^{\mathrm{c}}$ & $\mathbf{M}$ & $\begin{array}{c}\text { Site } \\
\text { source } \\
\text { distance } \\
(\mathbf{k m})\end{array}$ \\
\hline \multirow{7}{*}{ 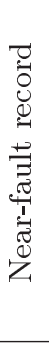 } & Imperial valley-06 & 181 & 1979 & 39 & El centro Array\#6 & 0.44 & 111.9 & 6.5 & 27.5 \\
\hline & Imperial valley-06 & 182 & 1979 & 37 & El centro Array\#7 & 0.46 & 108.9 & 6.5 & 27.6 \\
\hline & Irpinia. Italy-01 & 292 & 1980 & 40 & Sturno & 0.31 & 45.5 & 6.9 & 30.4 \\
\hline & Superstition-hills-02 & 723 & 1987 & 22.3 & Parachute test site & 0.42 & 106.8 & 6.5 & 16 \\
\hline & Loma Prieta & 802 & 1989 & 40 & Saratoga-Aloha & 0.38 & 55.6 & 6.9 & 27.2 \\
\hline & Erizican-Turkey & 821 & 1992 & 20.8 & Erizican & 0.49 & 95.5 & 6.7 & 9 \\
\hline & Cape Mendocino & 828 & 1992 & 36 & Petrolia & 0.63 & 82.1 & 7 & 4.5 \\
\hline \multirow{7}{*}{ 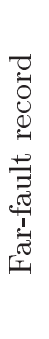 } & Northridge & 960 & 1994 & 20 & Canyon Country-WLC & 0.48 & 45 & 6.7 & 26.5 \\
\hline & Imperial valley & 169 & 1979 & 100 & Delta & 0.35 & 33 & 6.5 & 33.7 \\
\hline & Kobe, Japan & 1116 & 1995 & 41 & Shin-Osaka & 0.24 & 38 & 6.9 & 46 \\
\hline & Kocaeli, Turkey & 1158 & 1999 & 27.2 & Duzce & 0.36 & 59 & 7.5 & 98.2 \\
\hline & Landers & 900 & 1992 & 44 & Yermo Fire Station & 0.24 & 52 & 7.3 & 86 \\
\hline & Superstition Hills & 721 & 1987 & 40 & El Centro lmp. Co. & 0.36 & 46 & 6.5 & 35.8 \\
\hline & Chi chi, Taiwan & 1244 & 1999 & 90 & Chy101 & 0.44 & 115 & 7.6 & 32 \\
\hline
\end{tabular}

a Pacific Earthquake Engineering Research Center Strong Motion Database

b PGA: Peak Ground Acceleration

c PGV: Peak Ground Velocity 
scaled spectra for the near-fault and far-fault records are represented in Figure 2 in which their average is shown by the red line curve.

To scale the records through SM method, SeismoMatch [40] software was used to match the acceleration response spectrum of each $\mathrm{FF}$ and $\mathrm{NF}$ record and the target MCE spectrum. The MCE response spectrum was 1.5 times the DBE response spectrum level (Figure 2). SeismoMatch adjusted the accelerogram of the ground motions to match a specific spectrum using a wavelet algorithm. The records obtained were called spectrum-matched records. Each selected FF and NF record set was scaled using the amplitudescaling procedure in ASCE7 at the MCE level (Figure 2). Note that the LATBSDC allows for the use of both amplitude-scaling and spectrum-matching to obtain an appropriate ground motion data to carry out NLTHA [31].

\subsection{Earthquake intensity indices}

Earthquake intensity indices are useful parameters to study the characteristics of the ground motion records for seismic analysis. The simplest and most commonly used intensity indices are Peak Ground Acceleration (PGA) and Peak Ground Velocity (PGV). PGA is a parameter that is widely-used in seismic analysis, but the complex earthquake characteristics cannot be measured by this simple parameter. The ratio of $\mathrm{PGV}$ to PGA (PGV/PGA) is a compound intensity index of the effects of PGA and PGV. This ratio describes the frequency characteristics of ground motion, employed to show the intensity of near-fault ground motion. If the $\mathrm{PGV} / \mathrm{PGA}$ ratio is large, the ground motion may have a long-period velocity pulse [41].

The Arias intensity $\left(I_{A}\right)[42]$ is a measure of the energy content of a ground motion associated with earthquake duration. $I_{A}$ is defined as the integral over the duration of the square of the acceleration time history and is believed to be a good indicator of potential earthquake destructiveness. $I_{A}$ is calculated as:

$$
I_{A}=\frac{\pi}{2 g} \int_{0}^{t_{f}}(a(t))^{2} d t,
$$

where $g$ is gravity acceleration, $t_{f}$ is total duration of ground motion, and $a(t)$ is the time history of ground acceleration.

Mean period, $T_{m}$, measures the frequency content of a ground motion record. $T_{m}$ is one of the best indictors of frequency, because it includes all frequencies of engineering interest in the time history [43]. It is estimated as:

$$
T_{m}=\frac{\sum\left(C_{i}^{2} / f_{i}\right)}{\sum C_{i}^{2}},
$$

where $C_{i}$ is the Fourier amplitudes, and $f_{i}$ is the discrete Fourier transform frequency between 0.25 and $20 \mathrm{~Hz}$.

Table 4 shows the average intensity indices of different sets of records. As shown, the average PGA of the SM records did not differ significantly from the average PGA of the AS records, but the difference was considerable for the average PGV. As expected, the $\mathrm{PGV}$ of the NF events was much larger than PGV of the FF events due to the existence of a pulse. Spectrum matching decreased the PGV/PGA for the NF events more than for the FF events. This decrease was about $40 \%$ for the FF events. Spectrum matching primarily affects event velocity and pulse characteristics. $I_{A}$ of the SM records is almost half that of the AS records. This indicates that the energy content of the former is much less than that of the latter. $T_{m}$ for the FF events is the same for the AS and SM records. $T_{m}$ for the SM records was 0.67 times that for the AS records, which demonstrates that the frequency content of the NF events was affected by matching.

\section{Results of analysis}

The effect of scaling method on the behavior of SPH and EPH models subjected to NF and FF motion was studied and their responses were compared.

Figure 4(a) shows the flexural moment envelopes of the SPH and EPH models for the FF events; each plot shows four flexural moment envelopes, two from AS records and two from using SM records. Each graph is the average of the maximum response envelope calculated using 7 ground motion records in the NLTHA. The flexural moment envelopes were normalized using the product of the total seismic Weight and Height of the buildings $(W H)$. The height of the buildings was normalized, such that the roof height was one. It

Table 4. Average of intensity indices for ground motion record sets.

\begin{tabular}{lcccc}
\hline & NF-AS & NF-SM & FF-AS & FF-SM \\
\hline PGA $(\mathrm{g})$ & 1.17 & 1.09 & 1.02 & 0.88 \\
PGV (cm/s) & 224.45 & 131.53 & 162.19 & 122.62 \\
PGV/PGA (s) & 0.20 & 0.12 & 0.17 & 0.14 \\
Arias intensity (m/s) & 16.74 & 10.25 & 17.65 & 7.86 \\
Mean period (s) & 1.02 & 0.67 & 0.78 & 0.78 \\
\hline
\end{tabular}



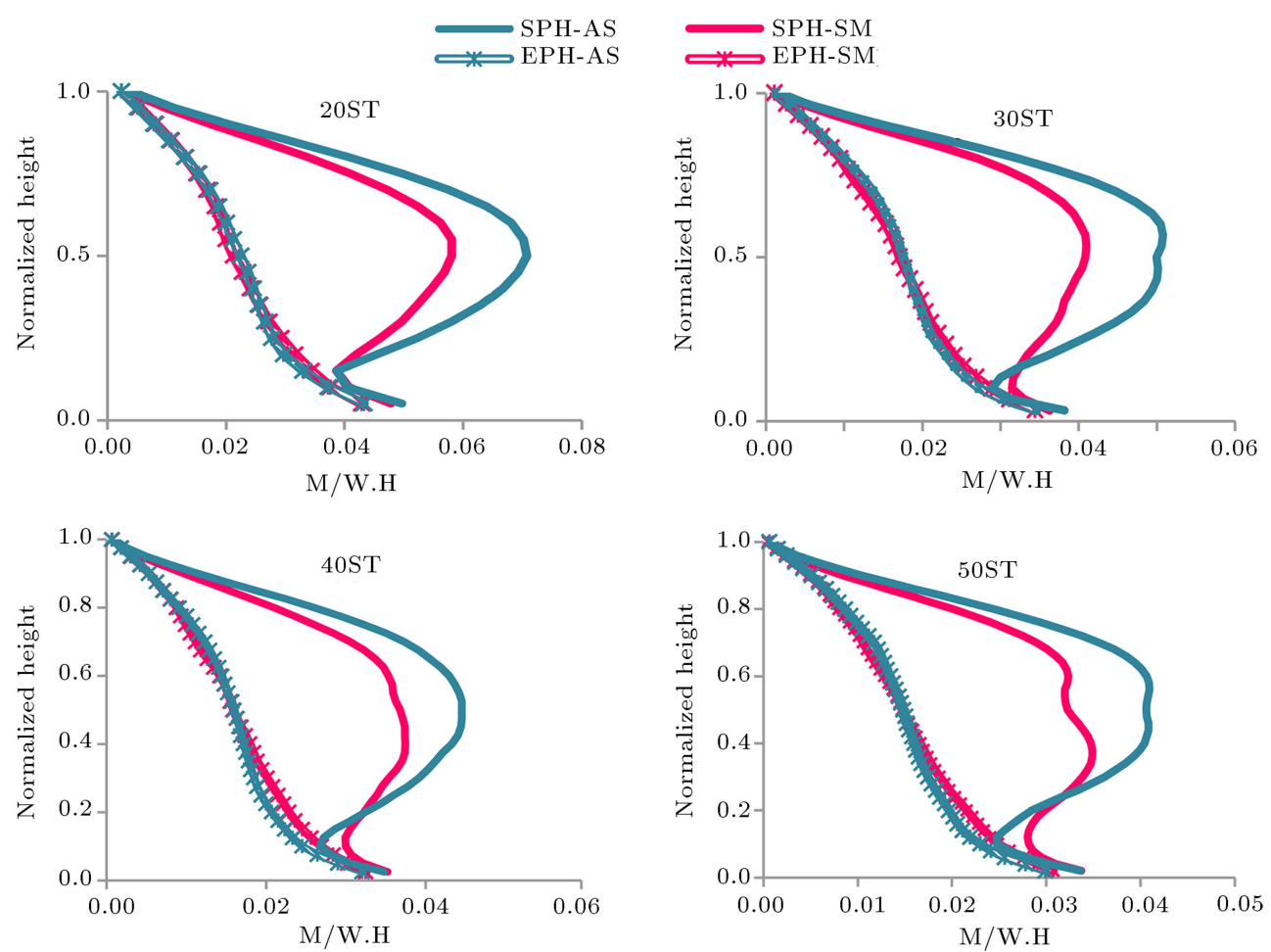

(a) Far-fault motion
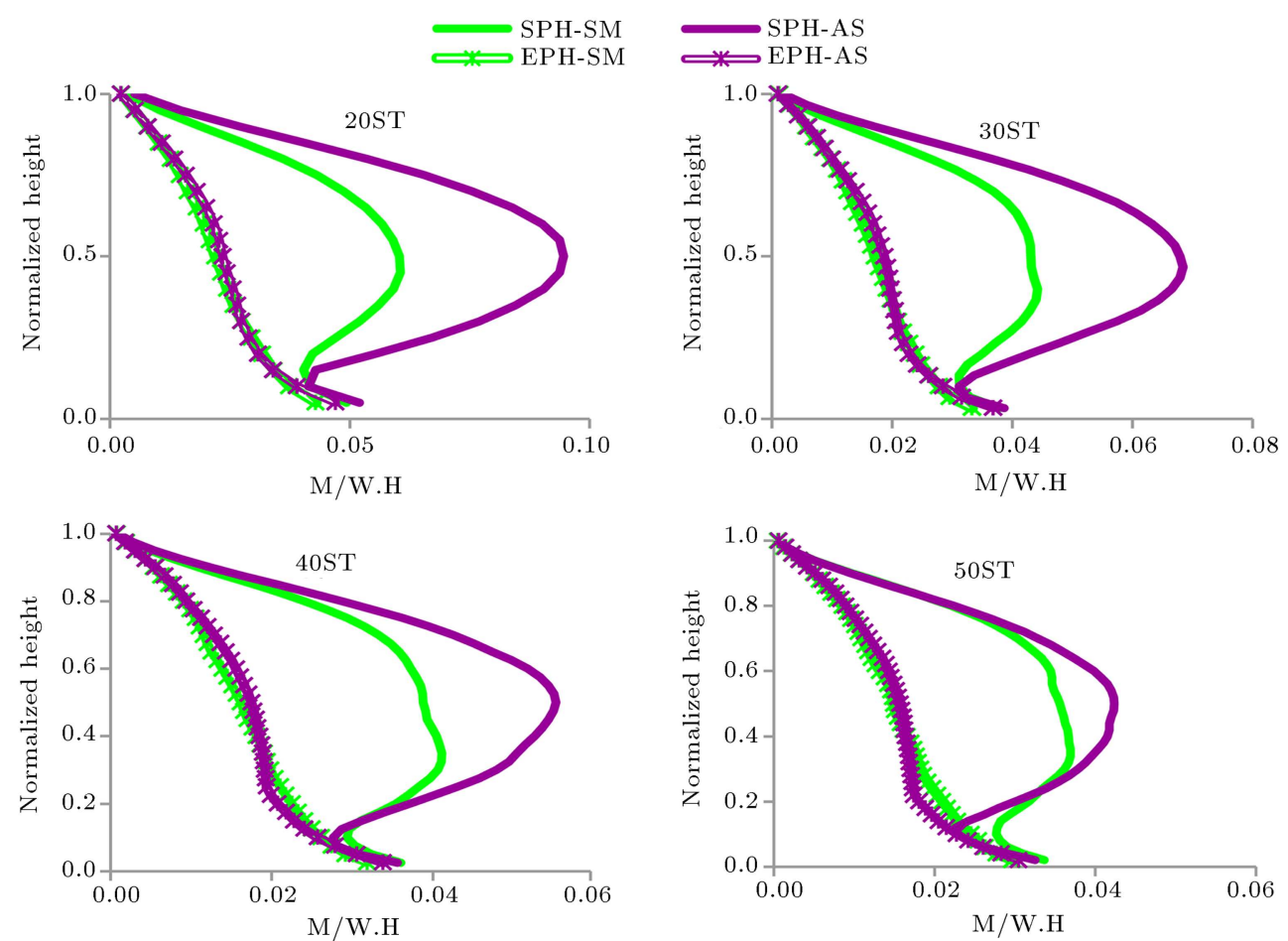

(b) Near-fault motion

Figure 4. Normalized flexural moment demand envelopes for (a) FF motion, and (b) NF motion.

was observed that the base moment demands resulting from dynamic analysis were approximately identical for all models of the same height, because the base moment exceeded the yielding moment. In the EPH models, the flexural moment demand along the height for the SM and AS records is in good agreement. As is demonstrated below, the reason for the different shapes of moment demand in the SPH and EPH models is the spreading of flexural plasticity through a large portion of the EPH core-wall models. 
Figure 4(a) shows that for SPH, the mid-height flexural moment obtained using SM records was approximately 0.75 times that of the flexural moment obtained using AS records. This indicates that spectrummatching caused the changes in the characteristics of the ground motion which resulted in less mid-height moment demand in the SPH models. For SPH, the shape of the flexural moment demand curve along the height differed significantly from the moment demand pattern obtained from EPH due to the significant contribution of the higher mode of vibration in the responses. When a plastic hinge occurs at the base during an earthquake, the upper parts are elastic and the relative contribution of the first mode responses decreases; the higher mode responses do not decrease significantly, creating excessive demand at mid-height.

Figure 4(b) plots the moment demand envelopes of the SPH and EPH models for NF motion. The overall configuration of the graphs is similar to that of FF motion. Again, the flexural moment envelopes were normalized using $W H$. The base moment exceeded the yielding moment in all the models. For SPH, it is evident that the taller the building, the smaller the difference between mid-height moment demands obtained using SM and AS records, because the difference between the levels of the SM and AS spectrums decreased when the building height and the vibration period increased; this was more serious for AS records.

Figure 5(a) shows the shear force demand envelopes from NLTHA in the SPH and EPH models subjected to FF motion for SM and AS records. The shear values were normalized using $W$. For SPH, the mean base shear demand resulting from the SM records was approximately 0.82 times the mean base shear demand resulting from AS records. One reason for this is that during the applicable period, the spectral acceleration of the SM records was generally lower than that of the AS records. For SPH models, shear demand above $0.75 \mathrm{H}$ indicates the effect of the higher modes of vibration.

Figure 5(b) shows the shear force envelopes for SPH and EPH approaches subjected to NF motion for $\mathrm{SM}$ and AS records. The trend of the graph is similar to that of FF motion. The shear demand envelope along the height for the SM records was again less than that for the AS records. For SPH models, as for the moment demand envelope, the difference between the shear demand envelopes resulting from the scaling procedures decreased for the taller buildings.

Curvature ductility demands caused plasticity to extend into the core-walls. Curvature ductility was calculated by dividing the maximum absolute curvature from NLTHA by the yield curvature. Yield curvature $\Phi_{y}$ was calculated by section analysis as $\Phi_{y}=0.0033 / L_{w}$ for all core-wall cross-sections, where $L_{w}$ is the core-wall length. The resulting yield curve was close to the value computed using the equation proposed by Paulay [13] for U-shaped walls as:

$$
\Phi_{y}=\frac{1.4 \varepsilon_{y}}{L_{w}}
$$

where $\varepsilon_{y}$ is the yield strain of steel bars and equals 0.00234. Figure 6(a) shows the mean curvature ductility demand envelopes for FF events subjected to AS and SM records. For SPH, it is evident that the base ductility demand for the 40- and 50-story buildings from the AS records was approximately 0.7 times the base ductility demand from the SM records. Each plot shows that the base curvature ductility demand of the SPH model was approximately twice as large as the base curvature ductility demand of EPH models of the same height. This occurred because, in the SPH models, plasticity was concentrated at the base of the core wall and, in the EPH models, plasticity extended to any point along the height. For all EPH models, curvature ductility demands increased exactly at the level where vertical reinforcement curtailment occurred.

EPH models subjected to SM records showed large curvature ductility demands at $0.2 H$, which approached or exceeded base curvature ductility demand. EPH models subjected to AS records showed a less significant increase in curvature ductility at lower levels, but showed a considerable increase at the upper levels of about $0.7 \mathrm{H}$. AS records generally caused less curvature ductility demand at the lower levels and more at the upper levels; curvature ductility demand at the upper levels of the EPH models approached that of base ductility demand. Conversely, SM records showed more curvature ductility demand at the lower levels of the core-walls and less curvature ductility at the upper levels. The reason for this considerable difference is the change in ground motion characteristics such as ground motion intensity caused by spectrum-matching.

Figure 6(b) shows the curvature ductility demand envelopes for cases subjected to NF events. The overall trend of the graphs is similar to those for the FF events. The difference between the curvature ductility demand for the AS and SM records was more significant due to the decrease in PGV and other intensity indices and the change in frequency content of the NF ground motions caused by spectrum-matching. For example, for the $\mathrm{EPH}$ model of the 30-story building, the curvature ductility demands from the AS and SM records at just above $0.2 H$ were 2 and 6.4 , respectively; these values at just above $0.8 H$ were 6.4 and 2.6, respectively. For the 50-story EPH model, the upper level ductility demand exceeded the base ductility demand. Note that, for all EPH cases, flexural yielding extension clearly developed in the upper levels of the core-wall above the boundary element regions dictated by ACI 318 . 

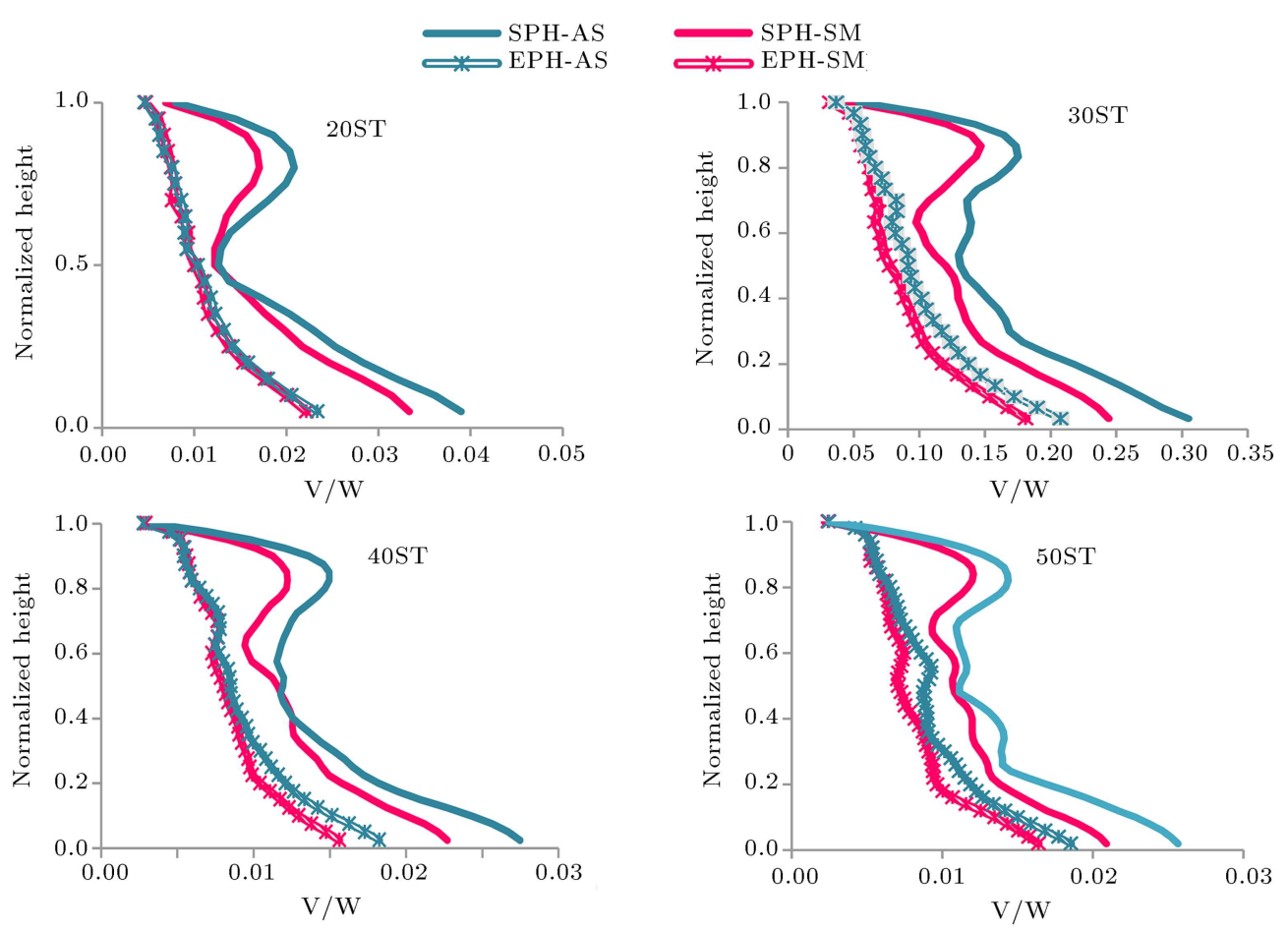

(a) Far-fault motion
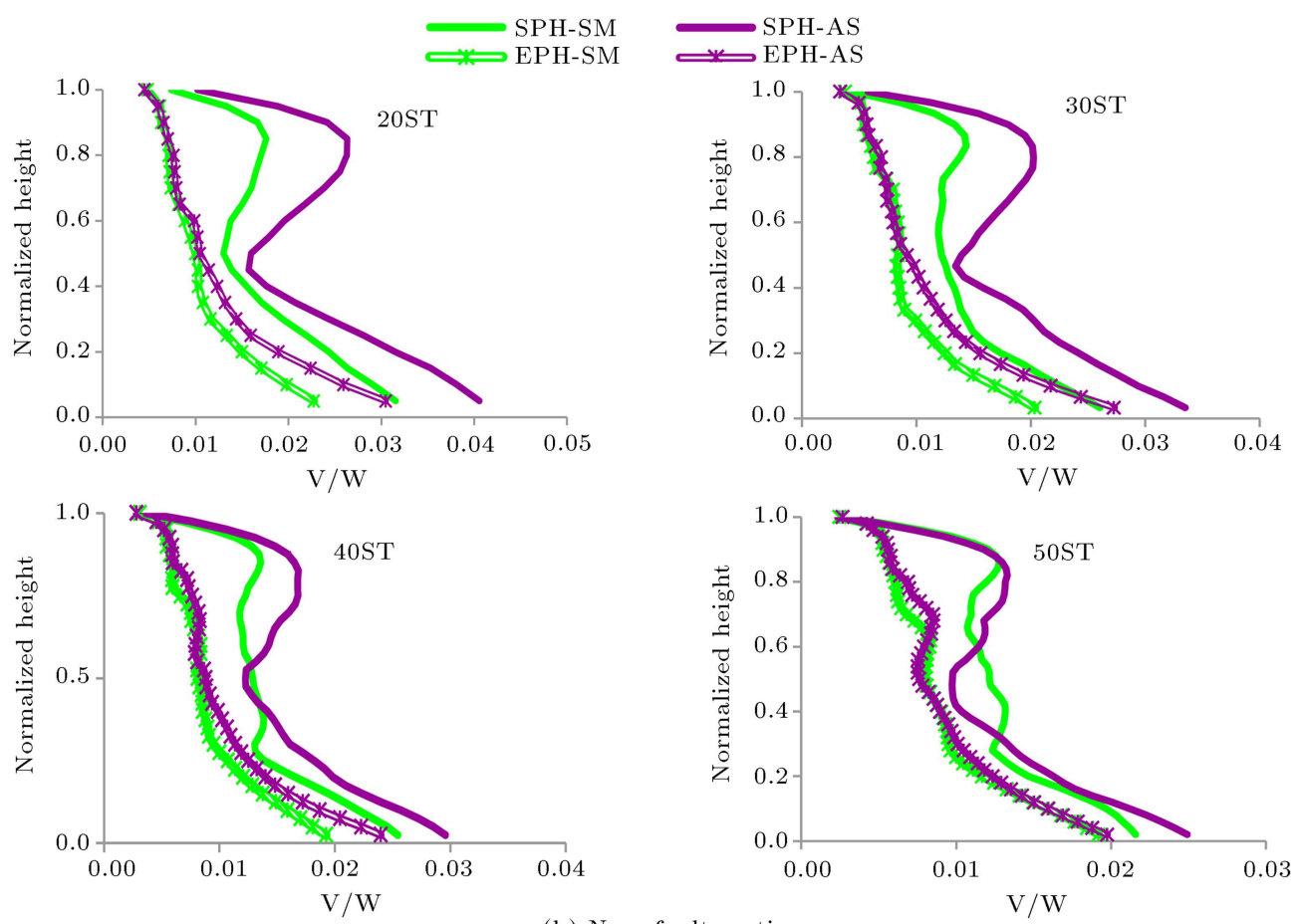

(b) Near-fault motion

Figure 5. Normalized shear demand envelopes for (a) FF motion, and (b) NF motion.

Sequence of plasticity extension in the RC corewalls depends on the characteristics of the earthquake records. Subjected to some other records, the plasticity first extends at the base region, and then in the upper region, this matter generally happens for AS-FF records.

Figure 7(a) shows the lateral displacement en- velopes resulting from the models subjected to FF events. For each case, lateral displacement was divided by the total height to obtain normalized displacement. Normalized roof displacement is called the roof drift ratio. The displacement graph of the EPH models was more curved than for the SPH models due to the extension of plasticity along the height of the model. 

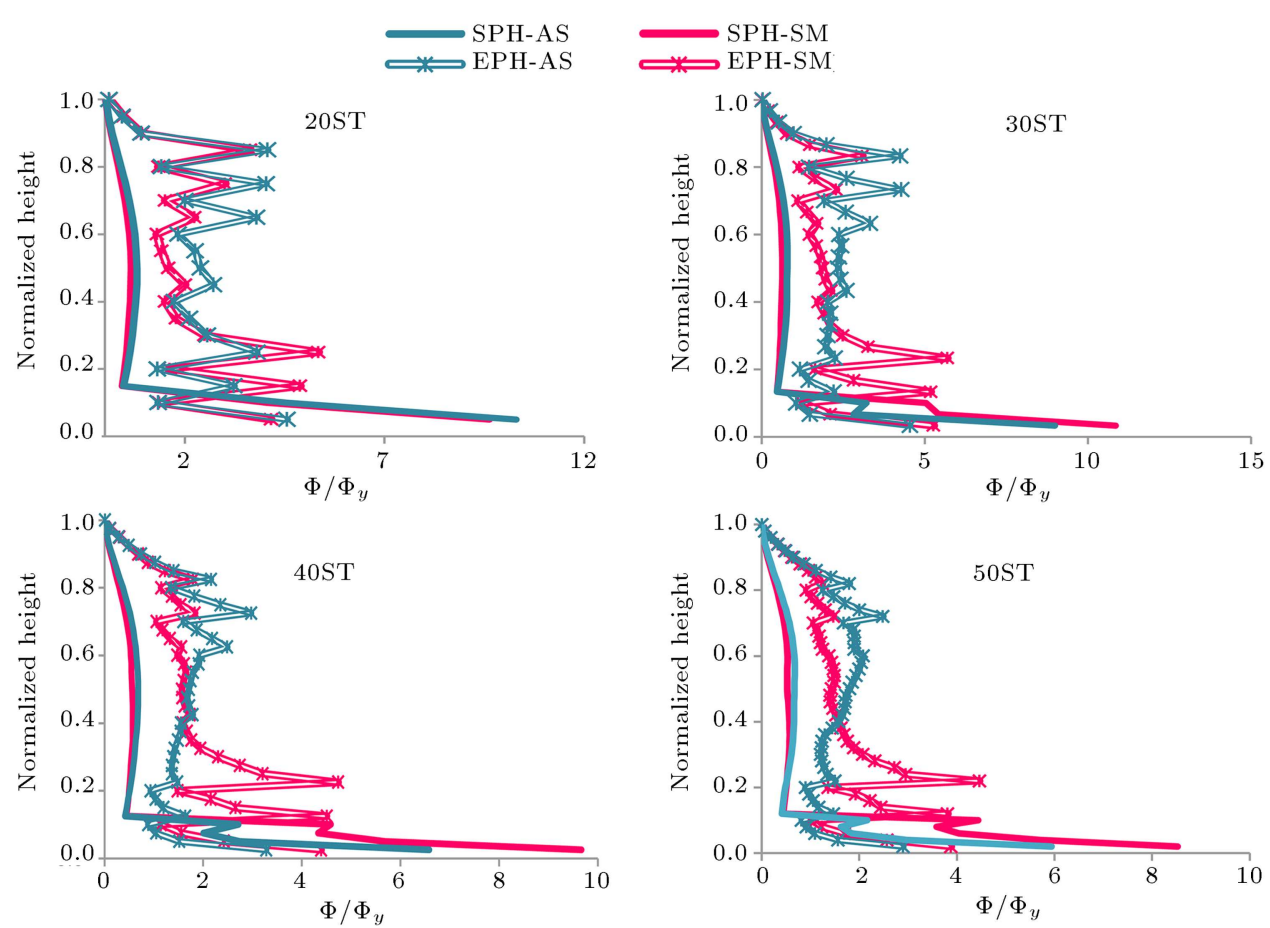

(a) Far-fault motion
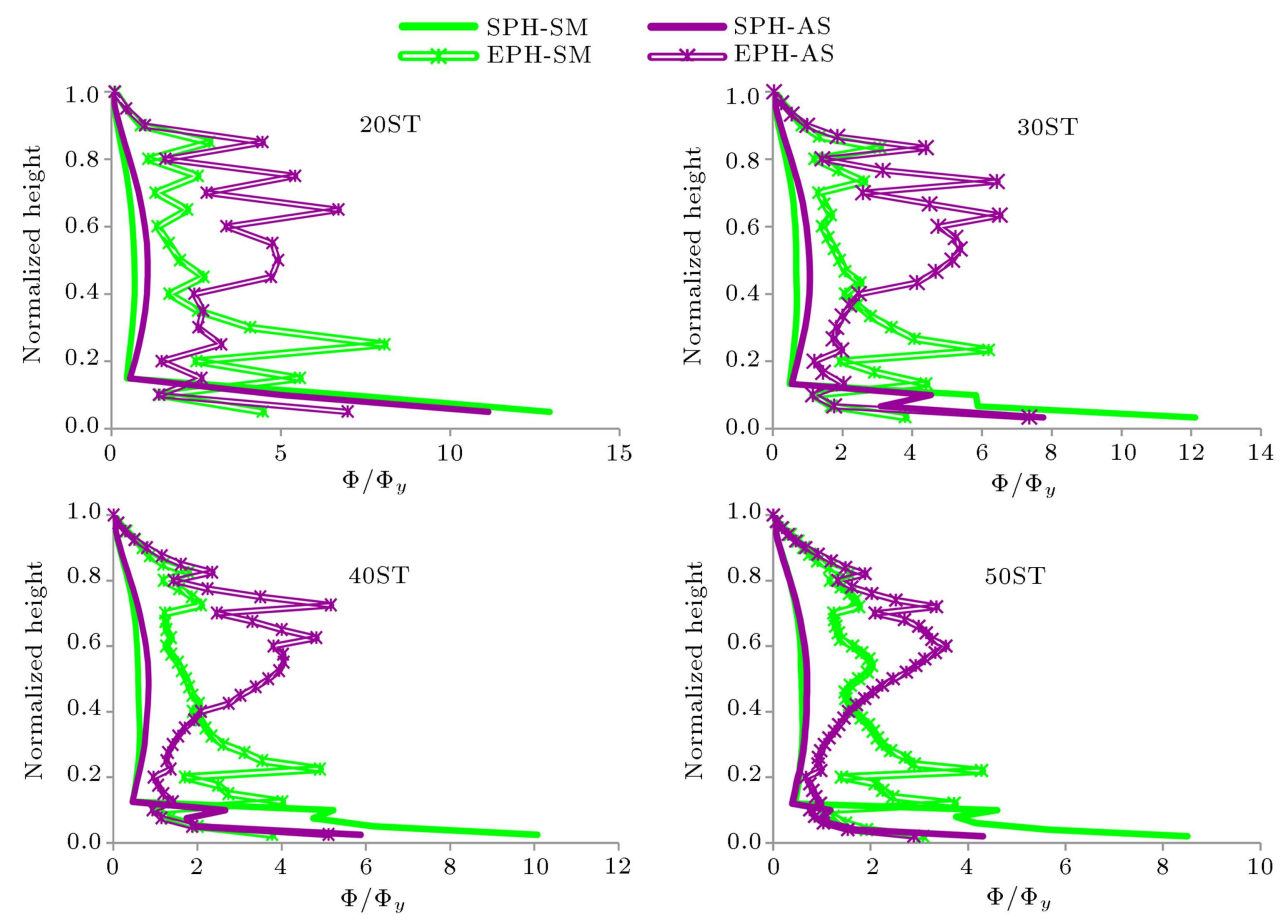

(b) Near-fault motion

Figure 6. Curvature ductility demand envelopes for (a) FF motion, and (b) NF motion.

For SPH models, plasticity was concentrated at the base of the core-wall, and the displacement graph of the upper levels was nearly linear. In each model, the roof drift ratio resulting from the AS record for both $\mathrm{SPH}$ and EPH was approximately equal. This is probably a result of the nearly constant spectral displacement for long-period structures. The results obtained using SM records showed that the roof drift ratio for $\mathrm{EPH}$ was about $15 \%$ larger than that for SPH. This occurred as a result of the large curvature ductility demand and inter-story drift demand at the lower levels of the EPH core wall subjected SM records. Except for the 20-story models, the roof drift ratio of the SPH models for the AS records was approximately 0.6 times the roof drift 

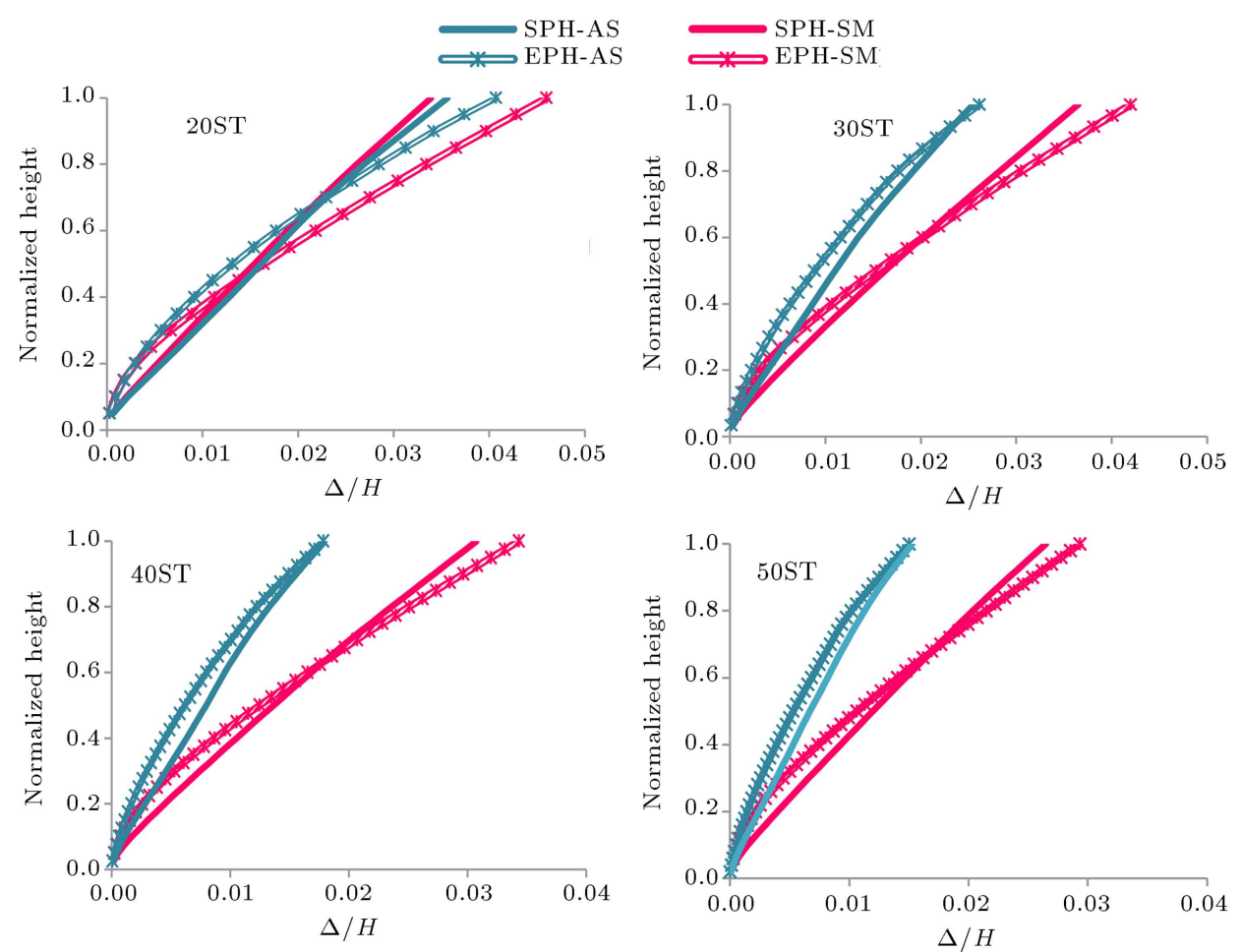

(a) Far-fault motion
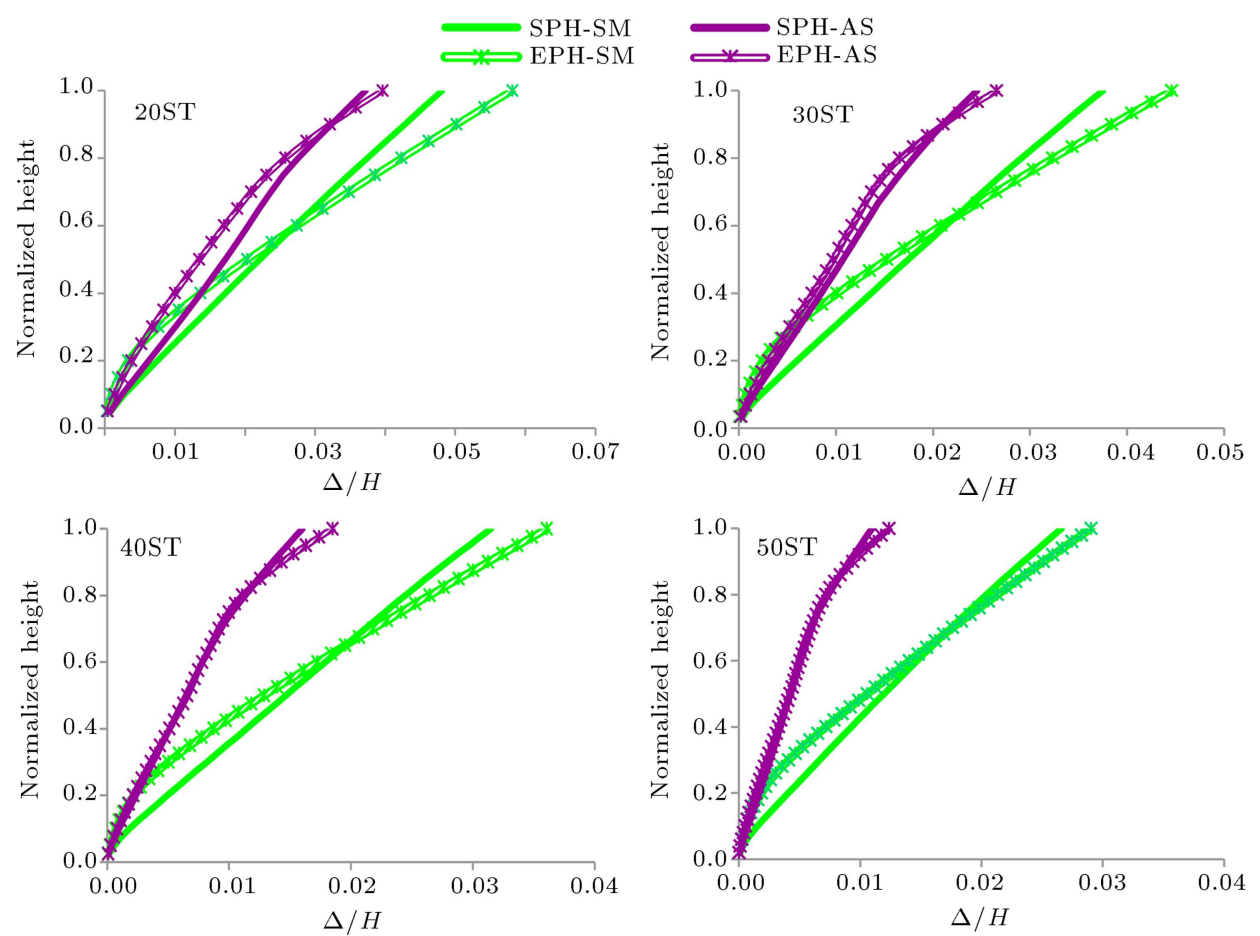

(b) Near-fault motion

Figure 7. Normalized displacement demand envelopes for (a) FF motion, and (b) NF motion.

ratio for the SM records; this coefficient was about 0.5 for the EPH models. This significant difference resulted from the effect of the different characteristics of the records.

Figure 7(b) shows the normalized displacement envelopes for the models subjected to NF events. The roof displacement for $\mathrm{SPH}$ and $\mathrm{EPH}$ from AS records did not differ significantly as for the NF events. For NF cases, roof displacement for the EPH models was slightly greater than that of the SPH models. It is evident that the 20-story models showed roof drift ratios of the SM records that were approximately 1.5 

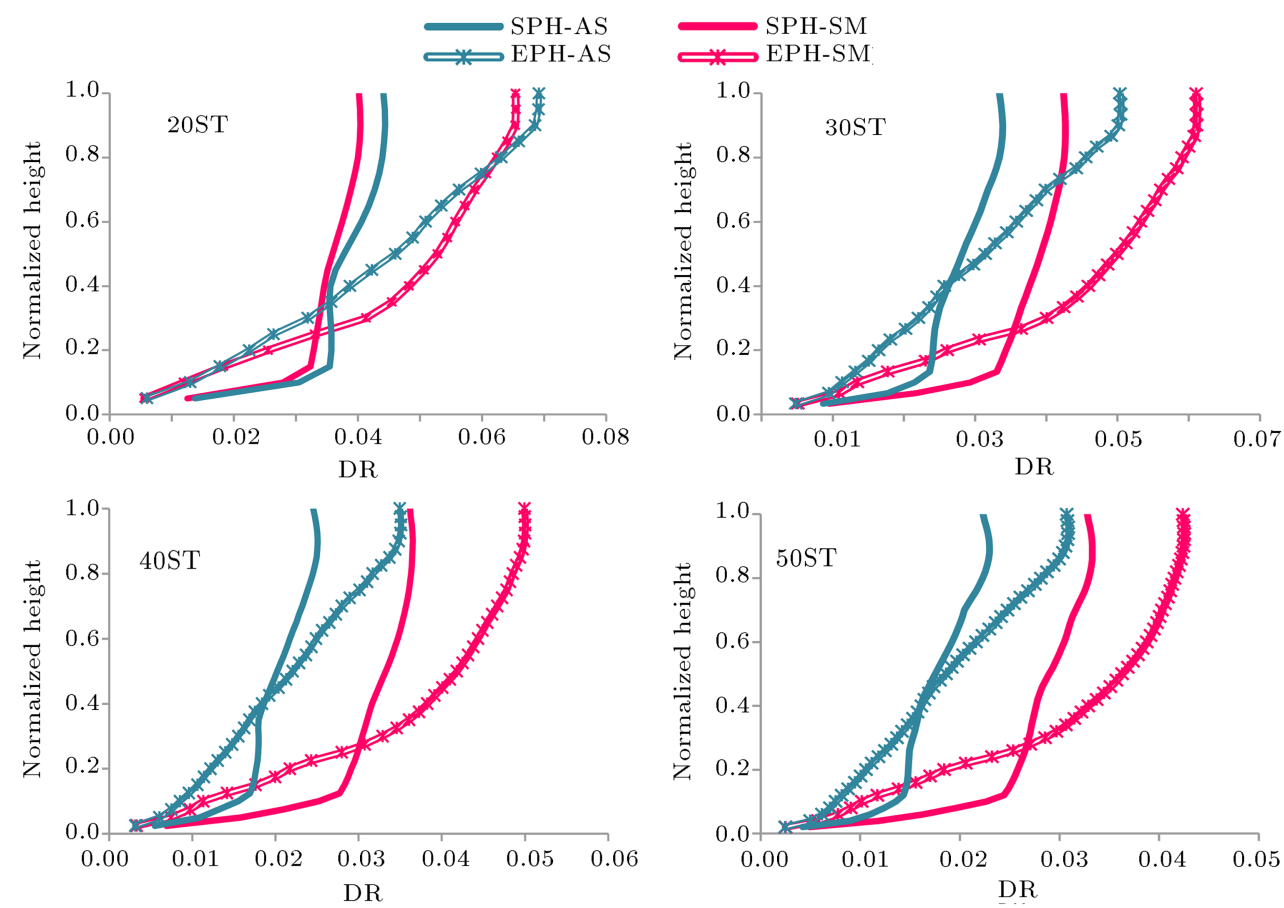

(a) Far-fault motion
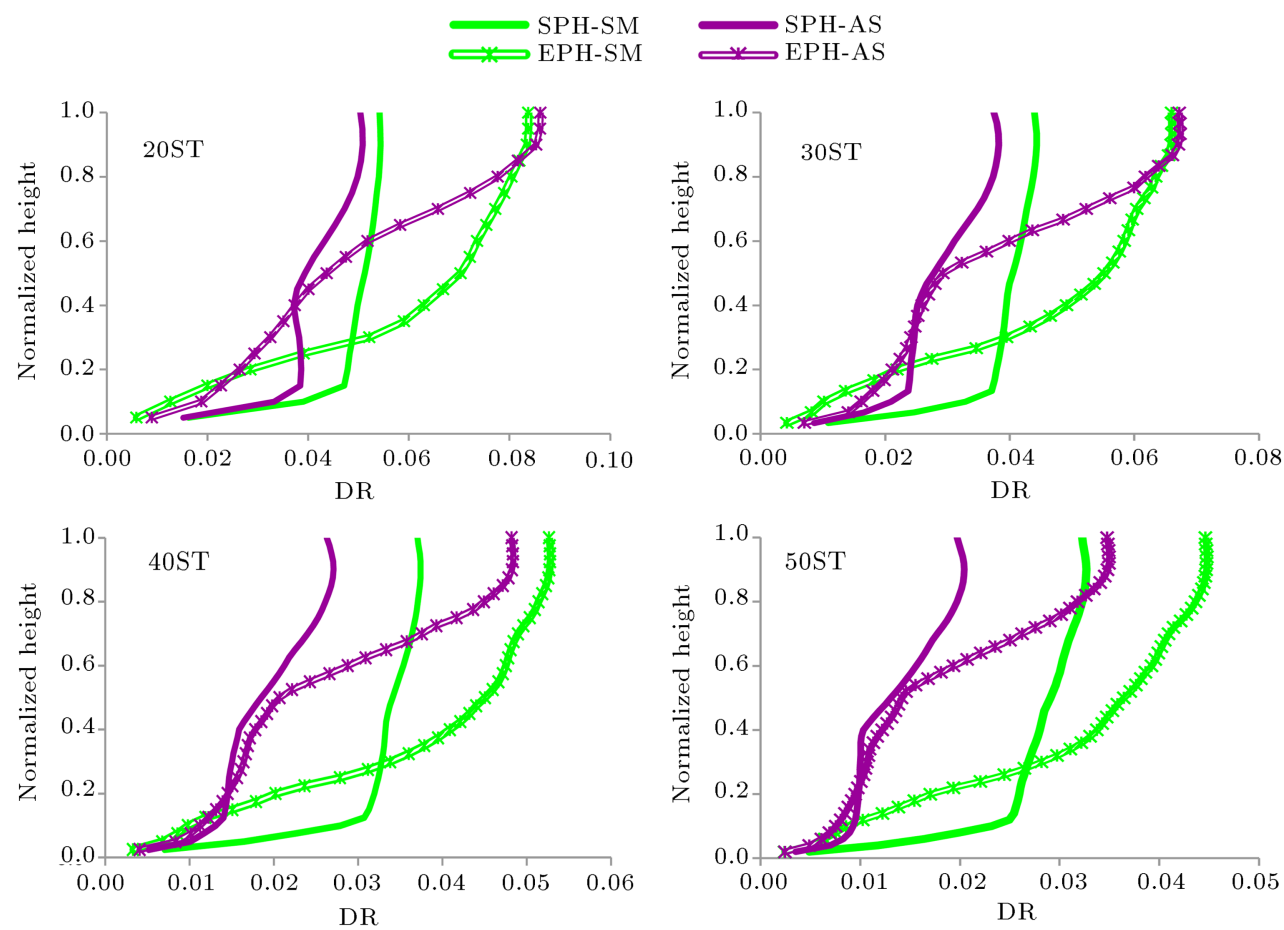

(b) Near-fault motion

Figure 8. IDR demand envelopes for (a) FF motion, and (b) NF motion.

times those of the AS records; this coefficient increased up to 2.4 for the 50-story building, which is a notably large value. The SM records caused larger curvature ductility demand or large inter-story demand at the lower levels and at the base of the core-walls. This increased top displacement over that of the AS records.

Figure 8(a) shows the Inter-story Drift Ratio
(IDR) envelopes for FF events. In all cases, the Maximum IDR (MIDR) occurred near the roof. Generally, the MIDRs of the EPH models were much larger than the MIDRs from the SPH models due to the extension of inelasticity along the height. For example, AS records for the 30-story buildings produced a maximum inter-story drift ratio in the SPH model that was 0.7 
times the MIDR in the EPH model, and a similar value was obtained for the SM records. Except for the 20story building, it is evident that for SPH models, the MIDR for the SM record was much larger than that for the AS records. For example, in the 40-story SPH model, the MIDR for the AS records was $2.5 \%$ and for the SM records was $3.6 \%$. In the SPH model, the difference between base curvature demand from the AS and SM records was greater for taller buildings and affected the IDR. LATBSDC (2011) stated that the MIDR, as the average response resulting from NLTHA using 7 records, should not exceed $3 \%$. It is obvious that this requirement has not been fulfilled in nearly all cases. More research is needed to investigate and assess the current record scaling methods to obtain appropriate records for NLTHA.

Figure $8(\mathrm{~b})$ shows the inter-story drift ratio envelopes along the height of all models subjected to NF events. The overall MIDR for the EPH models was much larger than that for the SPH models. The results for the AS records show that the MIDR in the SPH models was roughly 0.5 times the MIDR of the EPH models. For EPH models, the rapid increase in IDR at the upper levels for the AS records resulted from the large curvature demand caused by the extension of plasticity in these portions. For the taller buildings, the difference between the MIDR envelopes from the two scaling methods was greater due to the curvature demand.

It is important to note that the results and observations in this research are limited to the assumed condition and models. Therefore, more investigation is required to generalize the responses and results of this paper.

\section{Conclusions}

The behavior of 20-, 30-, 40-, and 50-story core-wall buildings was investigated using two record scaling methods. Spectrum-matching and amplitude-scaling methods were used to obtain the appropriate scaled records and the results were compared. Besides, SPH and EPH approaches and the fiber element method were used in dynamic analysis. NF and FF strong ground motions were used to perform NLTHA. The following conclusions were drawn from the results:

1. Spectrum-matching process did not change the average PGA of records significantly. Spectrummatching method decreased the PGV and PGV/PGA of the records; the decrease for NF events was greater than that for FF events. For example, the PGV of SM-NF is 0.58 times the $\mathrm{PGV}$ of AS-NF, and this coefficient is 0.73 for the FF record. Besides, for NF records, the pulse characteristics were weakened by performing Spectrum-matching process;

2. $I_{A}$ of the SM records was almost half that of the AS records. This indicates that the energy content of the former is much less than that of the latter;

3. For NF events, mean period of vibration $\left(T_{m}\right)$ for the SM records was 0.67 times that for the AS records. This issue shows that the frequency content of the SM-NF events was affected by spectrummatching. On the other hand, before and after spectrum-matching process, the mean period of the FF records was almost identical;

4. In SPH approaches subjected to FF and NF events, the mid-height flexural moment demand from the SM records was considerably less than the flexural moment from the AS records. This issue demonstrates that the AS records excite the upper levels more intensely, while the SM records excite the lower levels more severely;

5. In the SPH approaches subjected to FF as well as NF events, the base shear demand from SM records was approximately 0.8 times the base shear demand from AS records. One reason is the change in the earthquake record characteristics by spectrummatching process; another reason is that, in the applicable period, the spectral acceleration of the SM records was on average less than that of the AS records;

6. Curvature ductility demands at $0.8 H$ of $\mathrm{EPH}$ models subjected to AS-FF events were near the curvature ductility demand at the base of this model. Conversely, the SM-FF records showed large curvature ductility demand at $0.2 \mathrm{H}$ and less curvature ductility demand at the upper levels. The overall trend subjected to NF events was similar to that for the FF records, except that the difference between the curvature ductility demands of the AS and SM records was more severe. For example, in the 30-story building, the curvature ductility demands for the AS and SM records at just above $0.2 H$ were 2 and 6.4 , respectively, and they were 6.4 and 2.6 at just above $0.8 H$, respectively. This difference resulted from changes in ground motion records characteristics, such as $\mathrm{PGV} / \mathrm{PGA}, I_{A}$, and the frequency content caused by spectrummatching process. It is recommended that SM records not be used to evaluate the seismic response of core-wall buildings;

7. The roof drift ratio for the SM records was considerably larger than that for the AS records. This difference was more intense for taller buildings. For example, the 50-story models subjected to $\mathrm{NF}$ events recorded a roof drift ratio for the SM records that was approximately 2.4 times that for 
the AS records. The reason is the large curvature ductility demand at the lower levels of the core-wall subjected to SM records which produced a larger drift angle at the lower half of the height and larger roof displacement in the taller buildings. More research is required to assess the current spectrummatching method to obtain appropriate records for NLTHA;

8. In EPH models, the SM records increased rotation in the lower levels, which increased the IDR in the lower levels. This is the opposite of the results of the AS records, where the inter-story drift increased in the upper half of the core wall, especially for NF events. The reason for this is the changes in the ground motion characteristics.

\section{References}

1. Munir, A. and Wartnichai, P. "Optimal reduction of inelastic seismic demands in high-rise reinforced concrete core wall buildings using energy dissipating devices", Structural Design of Tall and Special Buildings, 22(7), pp. 543-568 (2011).

2. Calugaru, V. and Panagiotou, M. "Response of tall cantilever wall buildings to strong pulse-type seismic excitation", Earthquake Engineering and Structural Dynamics, 41(9), pp. 1301-1318 (2012).

3. Boroschek, R.L., Contreras, V., Kwak, D.Y. and Stewart, J.P. "Strong ground motion attributes of the 2010 Mw 8.8 Maule, Chile, earthquake", Earthquake Spectra, 28(1), pp. 19-38 (2012).

4. NZS 3101 "New Zealand standard, part 1 - the design of concrete structures", Standards New Zealand, Wellington, New Zealand (2006).

5. CEN EC8, Design of Structures for Earthquake Resistance, European Committee for Standardization: Brussels, Belgium (2004).

6. Priestley, M.N.J., Calvi, G.M. and Kowalsky, M.J., Displacement-Based Seismic Design of Structures, IUSS Press: Pavia, Italy, ISBN: 88-6198-000-6 (2007).

7. Moehle, J., Bozorgnia, Y., Jayaram, N., Jones, P., Rahnama, M., Shome, N., Tuna, Z., Wallace, J., Yang, T. and Zareian, F. "Case studies of the seismic performance of tall buildings designed by alternative means", Task 12 report for the Tall Buildings Initiative, Pacific Earthquake Engineering Research Center, PEER Report (2011).

8. Adebar, P., Mutrie, J. and DeVall, R. "Ductility of concrete walls: the Canadian seismic design provisions 1984 to 2004", Canadian Journal of Civil Engineering, 32(6), pp. 1124-1137 (2005).

9. Beiraghi, H., Kheyroddin, A. and Kafi, M.A. "Forward directivity near-fault and far-fault ground motion effects on the behavior of reinforced concrete wall tall buildings with one and more plastic hinges", 25(11), pp. 519-539 (2016).
10. Rutenberg, A. and Nsieri, E. "The seismic shear demand in ductile cantilever wall systems and the EC8 provisions", Bulletin of Earthquake Engineering, 4, pp. 1-21 (2006).

11. Ghorbanirenani, I., Tremblay, R., Léger, P. and Leclerc, M. "Shake table testing of slender RC shear walls subjected to eastern north America seismic ground motions", Journal of Structural Engineering, 138(12), pp. 1515-1529 (2012).

12. Luu, H., Ghorbanirenani, I., Léger, P. and Tremblay, R. "Numerical modeling of slender reinforced concrete shear wall shaking table tests under high-frequency ground motions", Journal of Earthquake Engineering, $\mathbf{1 7}(4)$, pp. 517-542 (2013).

13. Paulay, T. "Seismic displacement capacity of ductile reinforced concrete building systems", Bulletin of New Zealand Society for Earthquake Engineering, 36(1) (2003).

14. Panagiotou, M. and Restrepo, Jim. "Dual-plastic hinge design concept for reducing higher-mode effects on high-rise cantilever wall buildings", Earthquake Engineering and Structural Dynamics, 38, pp. 1359-1380 (2009).

15. Beiraghi, H. "Forward directivity near-fault and farfault ground motion effects on the responses of tall reinforced concrete walls with buckling-restrained brace outriggers", Scientia Iranica (In Press)

16. Anderson, J.C. and Bertero, V.V. "Uncertainties in establishing design earthquakes", Journal of Structural Engineering, 113(8), pp. 1709-1725 (1987).

17. Beiraghi, H. and Siahpolo, N. "Seismic assessment of RC core-wall building capable of three plastic hinges with outrigger", The Structural Design of Tall and Special Buildings, 26(2), p. e1306 (2017).

18. Dimakopoulou, V., Fragiadakis, M. and Spyrakos, C. "Influence of modeling parameters on the response of degrading systems to near-field ground motions", Engineering Structures, 53, pp. 10-24 (2013).

19. Beiraghi, H., Kheyroddin, A. and Kafi, M.A. "Energy dissipation of tall core-wall structures with multiplastic hinges subjected to forward directivity nearfault and far-fault earthquakes", The Structural Design of Tall and Special Buildings, 25(15), pp. 801-820 (2016).

20. Tajmir Riahi, H., Amouzegar, H. and Ale Saheb Fosoul, S. "Comparative study of seismic structural response to real and spectrum matched ground motions", Scientia Iranica A, 22(1), pp. 92-106 (2015).

21. Calugaru, V. and Panagiotou, M. "Seismic response of 20-story base-isolated and fixed-base reinforced concrete structural wall buildings at a near-fault site", Earthquake Engineering \& Structural Dynamics, 43, pp. 927-948 (2014). 
22. ASCE/SEI 7-05 "Minimum design loads for buildings and other structures", American Society of Civil Engineers, Reston, VA (2005).

23. Ibrahimbegovic, A. and Wilson, E.L. "A unified formulation for triangular and quadrilateral flat shell elements with six nodal degrees of freedom", Communications in Applied Numeral Methods, 7, pp. 1-9 (1990).

24. ACI 318-11 "Building code requirements for structural concrete and commentary", ACI Committee 318, Farmington Hills (2011).

25. ASCE/SEI 41-06 "Seismic rehabilitation of existing buildings (Including Supplement \# 1)", American Society of Civil Engineers, Reston, VA (2006).

26. Orakcal, K. and Wallace, J.W. "Flexural modeling of reinforced concrete walls-experimental verification", ACI Structural Journal, 103(2), pp. 196-206 (2006).

27. Beiraghi, H., Kheyroddin, A. and Kafi, M.A. "Nonlinear fiber element analysis of a reinforced concrete shear wall subjected to earthquake records", Transactions of Civil Engineering, 39(C2+), pp. 409-422 (2015).

28. PERFORM-3D, Nonlinear Analysis and Performance Assessment for 3D Structures, V.4.0.3. Computers and Structures, Inc., Berkeley, CA (2011).

29. PERFORM-3D, Nonlinear Analysis and Performance Assessment for 3D Structures, V.4, User Guide. Computers and Structures, Inc., Berkeley, CA (2006).

30. Mander, J.B., Priestley, M.N.J. and Park, R. "Theoretical stress-strain model for confined concrete", ASCE Journal of Structural Engineering, 114(8), pp. 1804-1826 (1988).

31. LATBSDC, An Alternative Procedure for Seismic Analysis and Design of Tall Buildings Located in the Los Angeles Region, Los Angeles Tall Buildings, Structural Design Council (2011).

32. Ghodsi, T., Ruiz, J.F., Massie, C. and Chen, Y. "Pacific earthquake engineering research/seismic safety commission tall building design case study", The Structural Design of Tall and Special Buildings, 19(2), pp. 197-256 (2010).

33. Powell, G., Detailed Example of a Tall Shear Wall Building Using CSI's Perform 3D Nonlinear Dynamic Analysis, Berkeley, CA: Computers and Structures Inc. (2007).

34. Priestley, M.N.J. and Grant, D.N. "Viscous damping in seismic design and analysis", Journal of Earthquake Engineering, 9(SP2), pp. 229-255 (2005).

35. Léger, P. and Dussault, S. "Seismic-energy dissipation in MDOF structures", Journal of Structural Engineering, 118(5), pp. 1251-1269 (1992).

36. Bernal, D. "Viscous damping in inelastic structural response", Journal of Structural Engineering, 120(4), pp. 1240-1254 (1994).
37. Chopra, A.K., Dynamics of Structures, Prentice-Hall, New Jersey (2001).

38. FEMA P695, Quantification of Building Seismic Performance Factors (ATC-63 Project), Federal Emergency Management Agency, Washington D.C. (2009).

39. Pacific Earthquake Engineering Research Center PEER Strong Motion Database, available at: www/http://peer. berkeley.edu/nga/.

40. SeismoMatch "A computer program for adjusting earthquake records to match a specific target response spectrum," Available at: http://www. seismosoft.com (2011).

41. Hadiani, N., Davoodi, M. and Jafari, M.K. "Correlation between settlement of embankment dams and ground motion intensity indices of pulse-like records", IJST, Transactions of Civil Engineering, 37(C1), pp. 111-126 (2013).

42. Arias, A. "A measure of earthquake intensity", R.J. Hansen, Ed., Seismic Design for Nuclear Power Plants, MIT Press, Cambridge, Massachusetts, pp. 438-483 (1970).

43. Rathje, E.M., Abrahamson, N.A. and Bray, J.D. "Simplified frequency content estimates of earthquake ground motions", J. Geotech. Geoenviron., 124, pp. 150-159 (1998).

\section{Biographies}

Hamid Beiraghi was born in 1979 in Sangesar, Iran. He obtained his BS degree in Civil Engineering from the Department of Civil Engineering at Sharif University of Technology, Tehran, Iran, in 2000, his first MS degree in Construction Management and Engineering from Tehran University, in 2002, his second MS degree in Earthquake Engineering from International Institute of Earthquake Engineering and Seismology, Iran, in 2006, and his PhD degree in Structural Engineering from Semnan University, Iran, in 2015. His research focuses on the tall building response under near-fault pulse-like earthquakes and design of core-wall structures. He has published more than 20 journal and conference papers, and one book. He is a Faculty Member of Azad University, Mahdishahr Branch, Sangesar, Iran. He has also supervised numerous MS thesis.

Ali Kheyroddin obtained his MS degree from Iran University of Science and Technology, Iran, and his PhD degree from McGill University, Canada. Currently, he is a Professor of Civil Engineering at Semnan University, Semnan, Iran, an Invited Visiting Scholar in the University of Texas at Arlington, USA, and he was the Chancellor of the Semnan University for 8 years. His research interests include design of reinforced concrete structures, tall buildings, rehabilitation of existing buildings, and design of earthquake resistant buildings. He is the author of eight books, more than 
50 ISI and ISC journal papers, and more than 230 conference papers. He has four patents, and has also supervised numerous $\mathrm{PhD}$ and MS degree theses.

Mohammad Ali Kafi obtained his MS degree from Tabriz University, Iran, and his $\mathrm{PhD}$ degree from University of Science and Technology, Tehran, Iran.
His research interests include design of steel structures, ductility increase of braces, and rehabilitation of existing buildings and design of earthquake resistant buildings. He is the author of one book, more than 10 ISI and ISC journal papers, and more than 50 conference papers. He has one patent, and has also supervised numerous $\mathrm{PhD}$ and MS degree. 